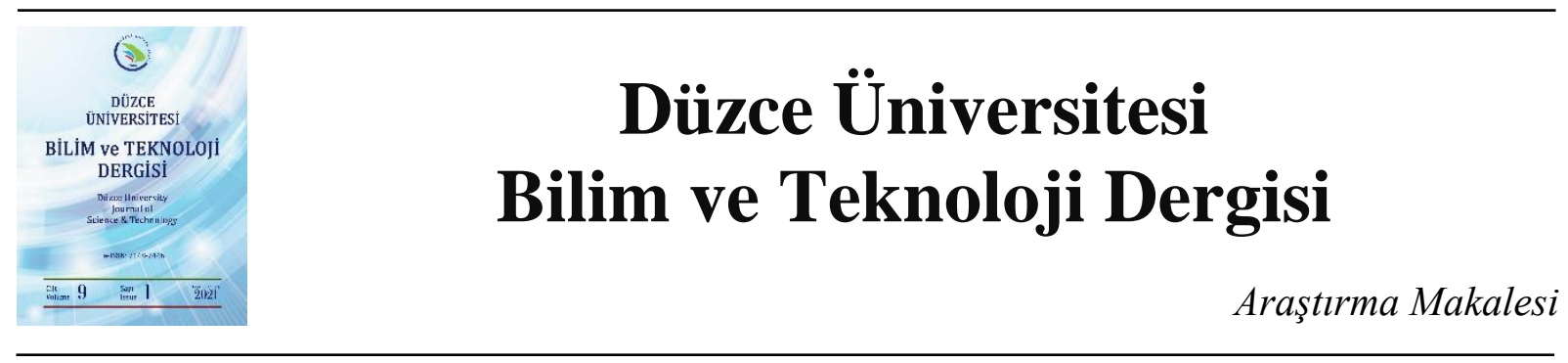

\title{
EKG Sinyallerini kullanarak Kalp Ritimlerinin Yapay Zekâ ile Sinıflandirılması
}

\author{
D Hamdi SAYIN ${ }^{\text {a }}$ (D) Osamah Khaled Musleh SALMAN ${ }^{a}$, (D) Bekir AKSOY ${ }^{\text {a,* }}$, (D) Utku KÖSE ${ }^{\text {b }}$ \\ ${ }^{a}$ Mekatronik Mühendisliği, Teknoloji Fakültesi, Isparta Uygulamalı Bilimler Üniversitesi, Isparta, TÜRKIYE \\ ${ }^{b}$ Bilgisayar Mühendisliği, Mühendislik Fakültesi, Süleyman Demirel Üniversitesi, Isparta, TÜRKIYYE \\ * Sorumlu yazarın e-posta adresi: bekiraksoy@isparta.edu.tr
}

DOI: $10.29130 /$ dubited.824362

\begin{abstract}
ÖZET
Günümüzde teknolojinin hızla ilerlemesi ile birlikte yapay zekâ yöntemleri de birçok alanda sıklıkla kullanılmaktadır. Yapay zekanın önemli kullanım alanlarından birisi de sağlık sektörüdür. Sağlık sektöründe erken teşhis, insan kaynaklı hataların minimuma indirilmesi gibi birçok durumda yapay zekâ yöntemleri kullanılmaktadır. Çalışmada açık kaynak erişimli internet sitesinden (kaggle.com) elde edilen 127710 adet EKG sinyallerine ait veri seti kullanılmıştır. Veri seti 100.710 adet eğitim, 1.500 adet veri de test ve kalan 25.000 adet veri ise doğrulama verisi olarak kullanılmıştır. Eğitim verileri için tasarlanan CNN modeli normal sinüs ritmi, supraventriküler erken atım, erken ventriküler kasılma, ventriküler ve normal atımın karışımı ve sınıflandırılamayan atım olmak üzere toplam beş sınıf için eğitilmiştir. Tasarlanan CNN modelinde hata oranı $\% 5,3$, duyarlık oranı $\% 94,4$, hassasiyet oranı $\% 94,6$, F-değeri ise $\% 94,4$ ve $\% 94,7$ doğruluk oranı olmak üzere beş farklı performans kriterine göre değerlendirilmiştir.
\end{abstract}

Anahtar Kelimeler: Yapay zekâ, EKG Sinyalleri, Sağlık, CNN

\section{Artificial Intelligence Classification of Heart Rhythms Using ECG Signals}

\begin{abstract}
Today, with the fast advancement of technology, artificial intelligence methods are frequently used in many areas. One of the important uses of artificial intelligence is the health sector. Artificial intelligence methods are used in many situations such as early diagnosis and minimization of human-induced errors in the health sector. In the study, the data set of 127710 ECG signals obtained from an open source website (kaggle.com) was used. The data set was used as 100,710 training data, 1,500 data as test and the remaining 25,000 data as validation data. Designed for training data, the CNN model was trained for a total of five classes: normal sinus rhythm, supraventricular premature beats, premature ventricular contraction, mixed ventricular and normal beats, unclassified beats. In the designed CNN model, the error rate $5.3 \%$, the sensitivity rate $94.4 \%$, the specificity $94.6 \%$, the F-value $94.4 \%$ and accuracy $94.7 \%$ was evaluated according to five different performance criteria.
\end{abstract}

Keywords: Artificial intelligence, EKG Signals, Health, CNN

Geliş: 11/11/2020, Düzeltme: 15/12/2020, Kabul: 21/12/2020 


\section{GIRIS}

Yapay zekâ, insan beyninin en temel özelliği olan öğrenme fonksiyonunu örnekler yardımı ile gerçekleştiren bilgisayar sistemleridir [1]. Yapay zekâ, makine öğrenmesi ve onun bir alt dalı olan derin öğrenme yöntemlerinden oluşmaktadır [2]. Derin öğrenme ses, metin, videolara ait bilgileri makine öğrenmesinden farklı olarak kodlar ile öğrenmek yerine bu öğelere ait simgelerden öğrenebilmektedir [3]. Uygulamada ise yapay zekâ daha sıklıkla bilgisayar ve bilişim alanlarında, insan gibi düşünebilen ve karar verebilen yapılar olarak karşımıza çıkmaktadır [4]. İnsan beyni ile benzer şekilde çalışan yapay zekâ çalışmaları günümüzde farklı alanlarda çıktılar vermesinin yanında kümeleme, tahminleme ve sınıflandırma gibi hedefler içinde uygulanmaktadır [5]. Yapay zekâ, birçok alanda gelişime devam etmekte, medikal sektöründe de yapay zekâ uygulamalarının sayısı her yıl katlanarak artmaktadır [6]. Bilişim sistemlerinin sıklıkla kullanıldığı alanlardan birisi de medikal uygulamalardır. Bilişim sektöründeki hızlı gelişmeler ile birlikte medikal cihazlardan elde edilen hastaya ait verilerin de dijital ortamda saklanarak gerektiğinde hızlı bir şekilde veriye ulaşılıp kullanılabilmesi mümkün olmaktadır [7]. Teknolojik gelişmelerin sağlık alanına uygulanması ile daha verimli çözümler üretilerek yaşam kalitesinin arttırılması sağlanmakta ve hastalık teşhisleri daha hızlı gerçekleşmektedir. Sağlık sektöründe önemli rahatsızlıklardan birisi de kalp rahatsızlıklarıdır. Günümüzde ani ölümlere neden olan kalp rahatsızlıklarının erken teşhisi ile çok sayıda hasta kaybının önüne geçilebilmektedir. Kalp rahatsızlıklarının teşhis yöntemlerinden biri de kalbin elektriksel aktivitesinin kayıt altına alınması sonucunda elde edilen elektrokardiyogram (İng. ElectroCardioGram-ECG) sinyal verilerinin yorumlanmasıdır. Bu sinyal verileri üzerindeki olağanüstü değişimler kalpte bir rahatsızlık olduğunu göstermekte ve bu durum hasta için oldukça tehlikeli sonuçlar doğurabilmektedir [8]. Bu tehlikelerin önceden kestirilebilmesi EKG verilerinin doğru bir biçimde tanımlanarak sınıflandırılması ile mümkün olmaktadır [9]. Yapay zekâ yöntemleri kullanarak veriden anlamlı sonuçlar çıkarma, medikal uygulamalarda tanı, tedavi ve sonucu öngörmede sıkl1kla kullanılan bir yöntemdir. [10].

Çalışmada EKG sinyallerine ait veri seti kullanılarak kalp ritimleri için Evrişimli Sinir Ağları (İng. Convolutional Neural Network-CNN) ile sınıflandırma işlemi gerçekleştirilmiştir. Elde edilen CNN modeli \%94,7 doğruluk oranında sinyalleri sınıflandırmıştır.

\section{MATERYAL VE METOT}

Çalışmada açık kaynak erişimli internet sitesinden (kaggle.com) temin edilen 127710 adet EKG sinyali veri seti olarak kullanılmıştır. Kullanılan veri seti ve CNN derin öğrenme yöntemi materyal bölümünde detaylı bir şekilde verilmiştir.

\section{A. MATERYAL}

\section{A. 1. Veri Seti}

Çalışmada kullanılan veri seti, kalp atışı sınıflandırmasında sıkça kullanılan MIT-BIH Aritmi veri seti ve PTB teşhis EKG veri setinden türetilen iki kalp sinyalinden oluşmaktadır. MIT-BIH Aritmi veri setinde 109446 adet kalp sinyali bilgisi 187 sütunda sayısallaştırılmış olarak yer almaktadır. Tablo 1'de görüldüğü gibi sinyal verileri beş kategoride sınıflandırılmıştır. EKG verilerinin frekansı $125 \mathrm{~Hz}$ 'dir. 
Tablo 1. MIT-BIH aritmi veri seti içeriği

\begin{tabular}{cccc}
\hline $\begin{array}{c}\text { Sınıf } \\
\text { Numarası }\end{array}$ & $\begin{array}{c}\text { Sınıf } \\
\text { Kategorisi }\end{array}$ & Sınıf Adı & $\begin{array}{c}\text { Örnek Veri } \\
\text { Sayısı }\end{array}$ \\
\hline 0 & N & Normal Sinüs Ritmi & 94635 \\
\hline 1 & S & Supraventriküler erken atım & 13285 \\
\hline 2 & V & Erken ventriküler kasılma & 8039 \\
\hline 3 & F & Ventriküler ve normal atımın karışımı & 7236 \\
\hline 4 & Q & Sinıflandırılamayan atım & 803 \\
\hline
\end{tabular}

Şekil 1'de kullanılan beş sınıfa ait rastgele örnek EKG grafikleri Python programlama dilinde hazırlanan bir yazılım ile çizdirilmiştir.
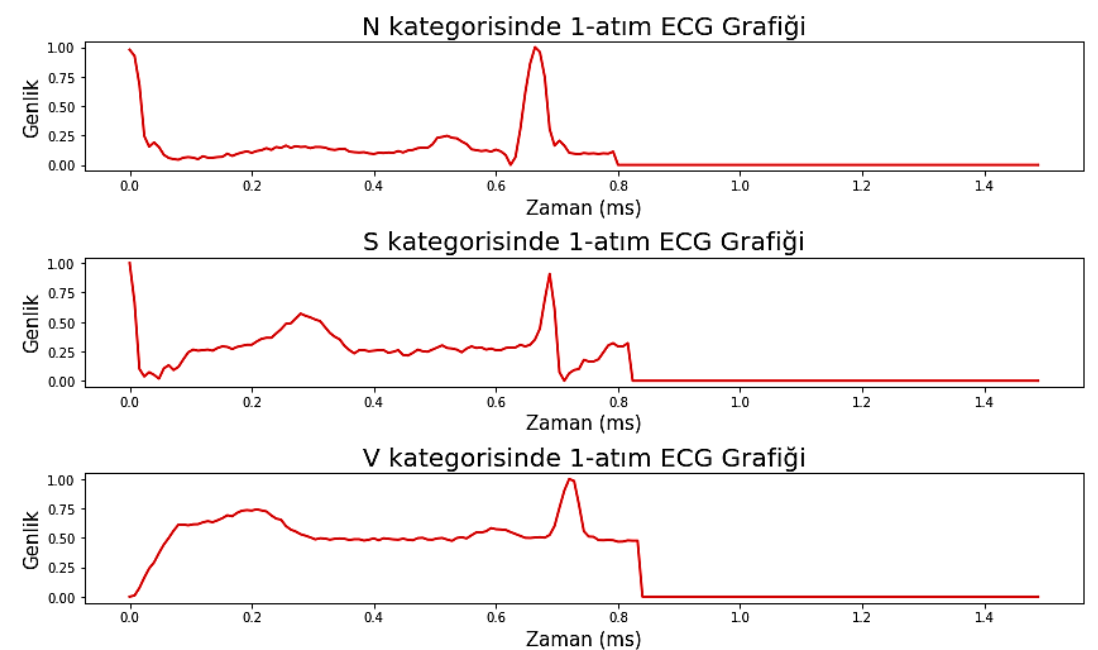

F kategorisinde 1-atım ECG Grafiğ

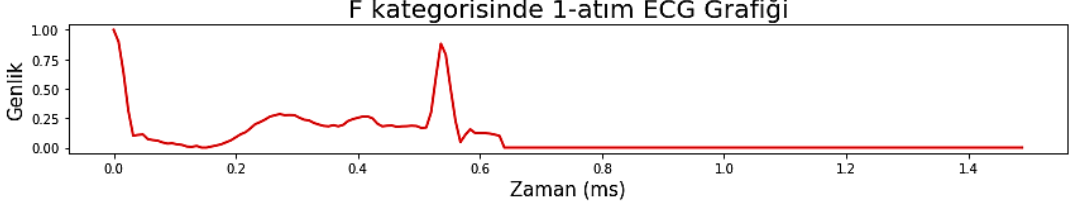

Q kategorisinde 1-atım ECG Grafiği

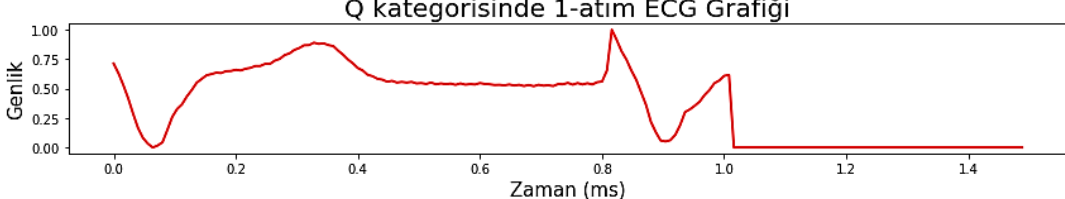

Sekil 1. MIT-BIH aritmi veri örnekleri

Çalışmada ikinci veri seti olarak PTB teşhis EKG veri setinde ise toplam 14552 adet sinyal bilgisi yer almaktadır. EKG verilerinin frekansı ise 125Hz'dir. Tablo 2'de PTB teşhis EKG sinyali için kullanılan iki sınıfa ait veri dağılımı verilmiştir. 
Tablo 2. PTB Teşhis EKG Veri tabanı İçeriği

\begin{tabular}{ccc}
\hline Sınıf Numarası & Sınıf Adı & Örnek Veri Sayısı \\
\hline 0 & Normal Sinüs Ritmi & 4046 \\
\hline 1 & Aritmi (Düzensiz Kalp Ritmi) & 10506 \\
\hline
\end{tabular}

\section{A. 2. CNN Derin Öğrenme Modeli}

Günümüzde CNN ve derin öğrenme tabanlı çözümler pek çok sorunda başarılı sonuçlar vermekte, görüntü tanıma, ses tanıma ve doğal dil işleme gibi birçok farklı alanda uygulanabilmektedir. CNN, biyolojiden ilham alınarak üretilen çok katmanlı yapay sinir ağlarının bir türevidir [11]. Derin öğrenmenin özelleşmiş bir mimarisi olan CNN özellikle görüntü ve sinyal işlemede oldukça başarılı bir yöntemdir [12]. CNN biyolojik süreçlerden ilham alınmış, özellik çıkarma ve sınıflandırmayı birleştirerek, görüntü piksellerinden veya diğer sinyallerden kalıpları tanımak üzere tasarlanmış ileri beslemeli Yapay Sinir Ağları (YSA) yapılarından oluşmaktadır. Geleneksel bir CNN mimarisi evrişim, aktivasyon, havuzlama ve tam bağlı olmak üzere dört katmandan oluşmaktadır [13]. Evrişim katmanı, seyrek yerel bağlantı ve ağırlık paylaşımı ile tanımlanır. Katmanların her bir nöronu girdinin bir alt yerel alanına bağlanır. Farklı nöronlar, görüntünün daha iyi temsilini elde etmek için birbirleriyle üst üste gelen girdinin farklı yerel alanlarına tepki verirler. Ayrıca, evrişim katmanının nöronları, aynı ağırlıkları paylaşan özellik haritalarında gruplanır. Böylece tüm prosedür, her bir haritanın filtreleri olan paylaşılan ağırlıklar ile birlikte, evrişime eşdeğer hale gelmektedir. Ağırlık paylaşımı ağ parametrelerinin sayısını önemli ölçüde azaltır, dolayısıyla verimliliği artıır ve aşırı öğrenmeyi (İng. overfitting) engellemesine yardımcı olmaktadır [13]. Evrişim katmanları genellikle giriş sinyalinin daha karmaşık özelliklerini yakalamak için doğrusal olmayan bir aktivasyon katmanı ile takip edilir [13]. Havuzlama katmanları aynı zamanda, küçük dikdörtgen değer kümelerini toplayarak, önceki katmanın örneklemesini yapmak için de kullanılır. Maksimum veya ortalama havuzlama genellikle giriş değerlerini sırasıyla maksimum veya ortalama değerle değiştirerek uygulanır [13]. Havuzlama katmanları, çıktının hassasiyetini küçük giriş değişikliklerine düşürür. Son olarak eklenen bir veya daha fazla yoğunluk tabakasının her birini sinıflandırma sonucunu üreten bir aktivasyon tabakası takip eder [13]. CNN'nin eğitimi diğer YSA'ya benzer şekilde, eğitim tabanlı metotlar ve hatanın geri yayılımı kullanılarak bir kayıp fonksiyonunu en aza indirgenerek gerçekleştirilir [13]. Şekil 2’te örnek bir CNN mimarisi gösterilmiştir.

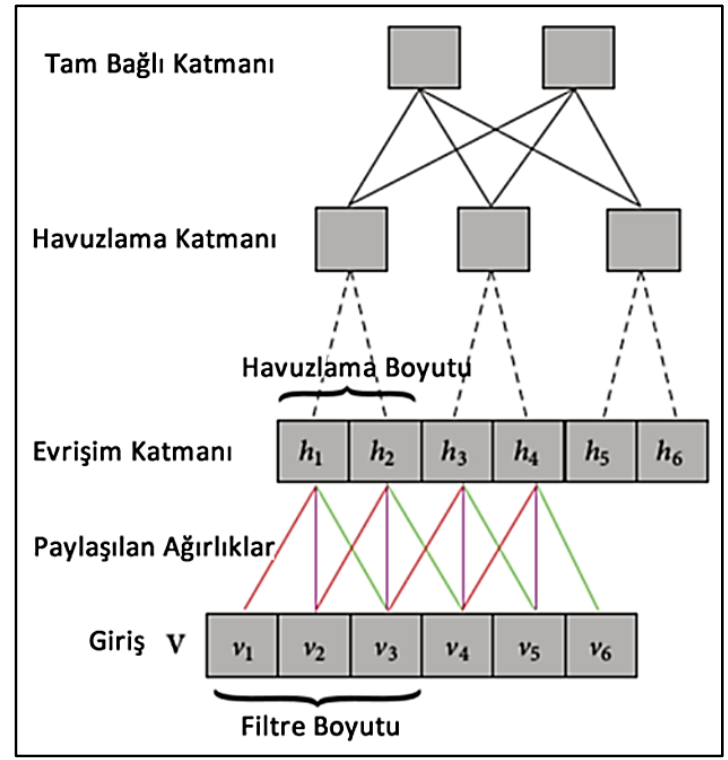

Şekil 2. Örnek bir CNN mimarisi [14] 


\section{A. 3. Sınıflandırma Algoritmalarının Performans Ölçütleri}

Büyük veri ve veri madenciliği alanında yapılan çalışmalarda sınıflandırma algoritmaları tarafindan üretilen sonuçların değerlendirilmesinde karmaşıklık matrisinden elde edilen, hata oranı, hassasiyet, Fdeğeri, doğruluk gibi ölçütler sıklıkla kullanılmaktadır. Karmaşıklık matrisinde, sınıflandırma değerleri Doğru Pozitif (DP), Yanlış Negatif (YN), Yanlış Pozitif (YP) ve Doğru Negatif (DN) olarak belirlenmiştir. Tablo 3’te karmaşıklık matrisi detaylı olarak gösterilmiştir.

Tablo 3. Karmaşıklık matrisi

\begin{tabular}{cccc}
\hline $\begin{array}{c}\text { KARMAŞIKLIK } \\
\text { MATRISI }\end{array}$ & \multicolumn{3}{c}{ Tahmin Edilen Sınıf } \\
\hline \multirow{3}{*}{ Mevcut Sınıf } & $\begin{array}{c}\text { Sinıf X } \\
\text { (Pozitif) }\end{array}$ & Doğru Pozitif (DP) & Yanlış Negatif (YN) \\
\cline { 2 - 2 } & $\begin{array}{c}\text { Sinıf Y } \\
\text { (Negatif) }\end{array}$ & Yanlış Pozitif(YP) & Doğru Negatif (DN) \\
& & & Sinıf Y (Negatif) \\
& & &
\end{tabular}

Doğruluk ölçütü, karmaşıklık matrisinde bulunan değerlerden, doğru sınıflandırılmış örnek sayısının toplam örnek sayısına oranıdır ve eşitlik 1'de verilen matematiksel ifade gösterilir. Hata ölçütü ise, karmaşıklık matrisinde yer alan yanlış sınıflandırılmış örnek sayısının toplam örnek sayısına olan oranı ile belirlenir ve eşitlik 2'de verilen matematiksel ifade kullanılarak elde edilir. Hata değerini hesaplamanın diğer bir yolu da 1 değerinden doğruluk değerinin çıkarılmasıdır [15].

$$
\begin{aligned}
& \text { Doğruluk }=\frac{D P+D N}{D P+Y N+Y P+D N} \\
& \text { Hata Oranı }=\frac{Y P+Y N}{D P+Y N+Y P+D N}
\end{aligned}
$$

Duyarlılık ve hassasiyet ölçümleri, karmaşıklık matrisi kullanarak hesaplanan diğer değerlendirme kriterlerindendir. Doğru sınıflandırılmış pozitif örnek sayısının (DP), doğru sınıflandırılmış pozitif örnek sayısı ve (DP) yanlış sınıflandırılmış negatif örnek sayısının (YN) toplamına oranı duyarlık ölçütünü ifade etmekte ve eşitlik 3 ile hesaplanmaktadır. Hassasiyet ölçümü ise doğru sınıflandırılmış pozitif örneklerin sayısının (DP) toplam pozitif örnek sayısına olan oranıdır ve eşitlik 4'e göre hesaplanır [16].

$$
\begin{aligned}
& \text { Duyarlık }=\frac{D P}{D P+Y N} \\
& \text { Hassasiyet }=\frac{D P}{D P+Y P}
\end{aligned}
$$

Duyarlık ve hassasiyet ölçümlerinin harmonik ortalaması $F$ değeridir ve Eşitlik 5'te verilen matematiksel ifade ile hesaplanmaktadır.

$$
F-\text { de } \breve{\mathrm{g}} e r i=\frac{2 D P}{2 D P+Y P+Y N}
$$


$\mathrm{Bu}$ ölçütler ikili sınıflandırma için kullanılırken üç veya daha fazla sınıftan oluşan sınıflandırma sonuçlarının değerlendirilmesinde makro ve mikro olmak üzere iki yöntem mevcuttur [17]. Makro yöntemde her sınıf için hesaplanan ölçümlerin ortalaması alınarak model başarısı değerlendirilirken, mikro yöntemde ise büyük sınıfa ait sonuçların etkin olduğu ağırlıklı bir değerlendirme yöntemi kullanılmaktadır [17]. Ortalama doğruluk, hata oranı, hassasiyet, duyarlılık ve F-değeri hesaplama işlemleri eşitlik 6-10'daki matematiksel ifadeler ile hesaplanmakta ve denklemlerdeki $l$ değeri sınıf sayısını ifade etmektedir.

Ortalama Doğruluk $=\frac{\sum_{i=1}^{l} \frac{D P_{i}+D N_{i}}{D P_{i}+Y N_{i}+Y P_{i}+D N_{i}}}{l}$

Ort. Hata Oranı $=\frac{\sum_{i=1}^{l} \frac{Y P_{i}+Y N_{i}}{D P_{i}+Y N_{i}+Y P_{i}+D N_{i}}}{l}$

Ort. Hassasiyet $=\frac{\sum_{i=1}^{l} \frac{D P_{i}}{D P_{i}+Y_{i}}}{l}$

Ort. Duyarllk $=\frac{\sum_{i=1}^{l} \frac{D P_{i}}{D P_{i}+Y N_{i}}}{l}$

Ort. F-de ğeri $=\frac{\sum_{i=1}^{l} \frac{2 D P_{i}}{2 D P_{i}+Y P_{i}+Y N_{i}}}{l}$

\section{B. METOT}

Çalışmada, oluşturulan veri seti üzerinde EKG sinyal verilerinin beş farklı kategoride sınıflandırılması için ön-eğitimli ağlar üzerinde çalı̧̧an bir CNN modeli tasarlanmıştır. Şekil 3’te görüldüğü gibi tasarlanan CNN modeli 4 evrişim ve 3 tam bağl1 katman olmak üzere toplam 7 katmandan oluşan bir mimariye sahiptir.

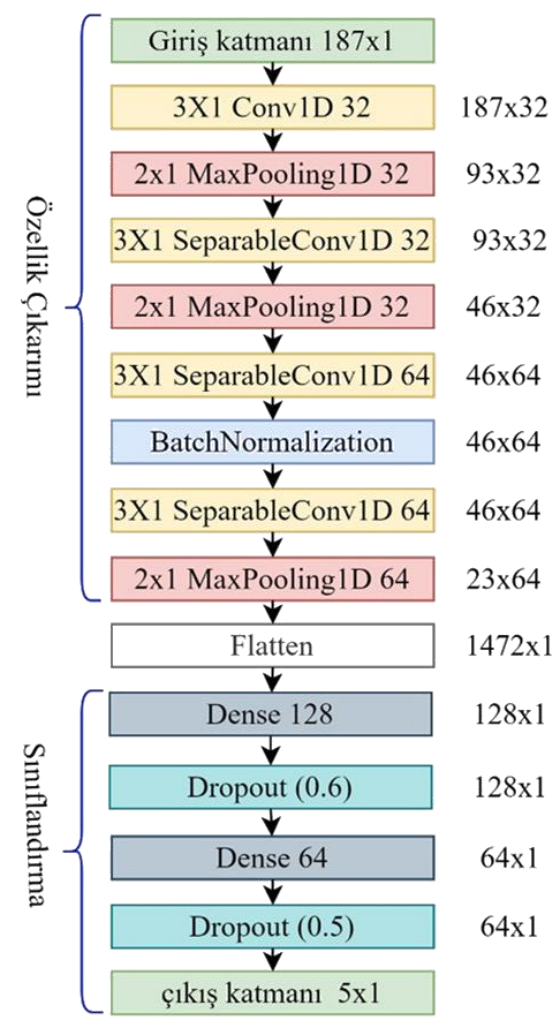

Şekil 3. Çalışmada kullanılan CNN mimarisi 
Çalışmada kullanılan veri seti, MIT-BIH Aritmi veri seti ve PTB teşhis EKG veri tabanının birleştirilmesi ile oluşturulmuştur. Veri seti toplamda 123998 kayit ve 188 sütundan oluşmaktadır. Tablo 4'te daha önceden sınıflandırılmış beş kategoriye ait veri türü ve sayıları verilmiştir.

Tablo 4. Çalışmada kullanılan veri türü ve sayıları

\begin{tabular}{ccc}
\hline Sınıf Numarası & Sınıf Adı & Örnek Veri Sayısı \\
\hline 0 & Normal Sinüs Ritmi & 98681 \\
1 & Supraventriküler erken atım & 23791 \\
2 & Erken Ventriküler kasılma & 8039 \\
3 & Ventriküler ve normal atımın & 7236 \\
& karışımı & \\
4 & Sinıflandırılamayan atım & 803 \\
\hline
\end{tabular}

Tabloda verilerin birleştirilmesi sonrasında 2, 3 ve 4 sınıflara ait veri miktarı diğer sınıflara göre sınırlı sayıda kaldığ 1 görülmektedir. Bu nedenle modelin yeterince veri ile desteklenerek daha isabetli tahminler yapabilmesini sağlamak amacıyla veri artırımı (İng.Data Augmentation) işlemi uygulanmıştır. Veri artırım işleminden sonra her sınıftan rastgele seçilen 300 adet veri alınarak elde edilen 1.500 kayıt ile modelin test veri seti oluşturulmuştur. Eğitim veri seti olarak 100.710, doğrulama veri seti olarak da 25.000 kayıt kullanılmıştır.

\section{ARASTIRMA BULGULARI}

CNN yöntemi kullanılarak elde edilen modelin doğruluğunu test etmek için karmaşıklık matrisi kullanılmıştır. Tablo 5'te tasarlanan model için 1.500 veri üzerinde yapılan tahminleme işlemi sonrası oluşan karmaşıklık matrisi verilmiştir.

Tablo 5. Karmaşıklık matrisi

\begin{tabular}{|c|c|c|c|c|c|c|}
\hline \multirow{6}{*}{ 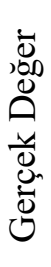 } & $N$ & 295 & 3 & 1 & 0 & 1 \\
\hline & $S$ & 19 & 280 & 1 & 0 & 0 \\
\hline & V & 9 & 3 & 287 & 1 & 0 \\
\hline & $F$ & 17 & 2 & 11 & 270 & 0 \\
\hline & $Q$ & 4 & 4 & 3 & 0 & 289 \\
\hline & & $N$ & $S$ & $V$ & $F$ & $Q$ \\
\hline & \multicolumn{6}{|c|}{ Tahmin Edilen Değer } \\
\hline
\end{tabular}

Karmaşıklık matrisi incelendiğinde beş farklı sınıfa ait doğru ve yanlış tahmin değerleri görülmektedir. Karmaşıklık matrisindeki sonuçlar incelendiğinde tasarlanan CNN modelinin yüksek bir doğruluk oranında sınıfları tespit ettiği görülmektedir.

Modelin test setinde yer alan sınıflara ait verilerin eşit sayıda olmasından dolayı çoklu sınıf değerlendirme tekniklerinden makro hesaplama yöntemi tercih edilmiştir. Tablo 5'ten yararlanılarak yapılan hesaplamalara göre oluşturulan modelin tahminleme doğruluk oranı $\% 94,7$ olarak belirlenmiştir. Performans değerlendirme kriterlerine ait sonuçlar Tablo 6' da gösterilmiştir. 
Tablo 6. Modelin performans kriterleri

\begin{tabular}{cccccc}
\hline & Doğruluk & Hata Oranı & Duyarlık & Hassasiyet & F-değeri \\
\hline CNN modeli & $\% 94,7$ & $\% 5,3$ & $\% 94,4$ & $\% 94,6$ & $\% 94,4$ \\
\hline
\end{tabular}

\section{IV.SONUC}

Yapay zekâ yöntemleri birçok farklı alanda olduğu gibi sağlık alanında da sıklıkla kullanılmakta ve birçok hastalığın erken teşhis edilmesinde büyük bir rol oynamaktadır. İnsan hayatını riske atan hastalıkların erken ve doğru bir şekilde teşhis edilmesi bu hastalıklardan kaynaklanan ölüm sayısının önüne geçilmesini sağlayacaktır.

Çalışmada açık erişimli internet sitesinden (kaggle.com) elde edilen EKG sinyalleri CNN derin öğrenme yöntemi ile sınıflandırılmıştır. Modelin sınıflandırma başarısı farklı performans ölçüm kriterlerine göre değerlendirilmiştir. Elde edilen sonuçlar aşağıda maddeler halinde verilmiştir.

- İlk olarak CNN derin öğrenme modeli için Karmaşıklık matrisi değerlendirme kriterine göre modelin değerlendirilmesi gerçekleştirilmiştir. Modelin değerlendirilmesi ile N sinıfina ait 300 sinyalden $295^{\prime}$ 'ni, S sinıfina ait 300 sinyalden 280'ni, V sinıfina ait 300 sinyalden 287'sini, F sinıfina ait 300 sinyalden 270'ni, Q sinıfina ait 300 sinyalden 289'nu, toplamda ise 1500 test verisi içerisindeki beş farklı sınıfa ait 1421 sinyali doğru sinıflandırdığı gözlemlenmiştir.

- İkinci olarak CNN derin öğrenme modelinin; doğruluk, hata oranı, duyarlılık, kesinlik ve F-ölçüsü ölçütlerinden oluşan performans ölçüm kriterlerine göre başarı oranı incelenmiştir. Değerlendirme sonucunda modelin \%94,4 doğruluk, \%5,3 hata oran1, $\% 94,4$ duyarlık, \%94,6 kesinlik ve \%94,4 F-ölçüsü değeri ile başarılı tahmin gerçekleştirdiği belirlenmiştir.

Çalışmada elde edilen sonuçlar ile kalp rahatsızlıklarının erken teşhisi için yapay zekâ tabanlı bir model önerilmiştir. Önerilen bu model ile yapay zekânın sağlık alanındaki uygulamaları için akademik literatüre katkı verilmesi amaçlanmıştır. İlerideki akademik çalışmalarda farklı yapay zekâ modelleri kullanılarak doğruluk oranının arttırılması hedeflenmektedir.

TEȘEKKÜR: Çalışmada “MIT-BIH Aritmi Veri seti” ve "PTB Teşhis EKG” veri setlerini açık kaynak erişimli internet sitesine (kaggle.com) aktaran kişi/kişilere teşekkürlerimizi sunarız.

\section{KAYNAKLAR}

[1] N. Buduma, Fundamentals of Deep Learning, USA: O’Reilly Media, 2015.

[2] A.Salouhou, "El yazısı karakter tanıma ve resim sınıflandırmada derin öğrenme yaklaşımları," Yüksek Lisans tezi, Lisansüstü Eğitim Enstitüsü, Fatih Sultan Mehmet Vakıf Üniversitesi, İstanbul, Türkiye, 2019.

[3] U. Kaya ve A. Yılmaz, Derin Öğrenme, Türkiye: Kodlab, 2019.

[4] S. Büyükgöze, E. Dereli, "Dijital sağlı uygulamalarında yapay zeka," VI. Uluslararası Bilimsel ve Mesleki Çalışmalar Kongresi, Ankara, Türkiye, 2019. 
[5] M. Atalay ve E. Çelik, "Büyük veri analizinde yapay zekâ ve makine öğrenmesi uygulamalarıartificial intelligence and machine learning applications in big data analysis," Mehmet Akif Ersoy Üniversitesi Sosyal Bilimler Enstitüsü Dergisi, c. 9, s. 22, ss. 155-172, 2017, doi: 10.20875/makusobed.309727.

[6] U. Bilge, "Tıpta yapay zeka ve uzman sistemler," Türkiye Bilişim Derneği Kongresi, İstanbul, Türkiye, 2007.

[7] Y. Yücel, A. Aytekin A. Ayaz ve F. Tüminçin, "Bilişim sistemlerinin sağlık sektörü açısından önemi," Avrasya Sosyal ve Ekonomi Araştırmaları Dergisi, c. 5, s. 8, ss. 147-155, 2018.

[8] Y. Ozbay, R. Ceylan ve B. Karlik, "A fuzzy clustering neural network architecture for classification of EKG arrhytmia's," Computers in Biology and Medicine, c. 36, s. 4, ss. 376-388, 2006.

[9] R. Ceylan, Y. Ozbay ve B. Karlik, "Classification of EKG arrhythmias using type-2 fuzzy clustering neural network," 14th National Biomedical Engineering Meeting, İzmir, Türkiye, 2009.

[10] A. Demirhan, Y. Kılıç ve G. İnan, “Tıpta yapay zeka uygulamaları,” Yoğun Bakım Dergisi, c. 9, s. 1, ss. 31-41, 2010.

[11] A. Nguyen, J. Yosinski and J. Clune, "Deep neural networks are easily fooled: High confidence predictions for unrecognizable images," Proceedings of the IEEE conference on computer vision and pattern recognition, Boston, USA ,2015.

[12] C.D. Rodin, L.N. de Limade, F.A. de Alcantara, Andrade, D.B Haddad, T.A. Johansen ve R. Storvold, "Object classification in thermal images using convolutional neural networks for search and rescue missions with unmanned aerial systems," International Joint Conference on Neural Networks (IJCNN), Rio de Janeiro, Brazil, 2018.

[13] İ. Özkan ve E. Ülker, "Derin öğrenme ve görüntü analizinde kullanılan derin öğrenme modelleri," Gaziosmanpaşa Bilimsel Araştırma Dergisi, c. 6, s. 3, ss. 85-104, 2017.

[14] M. Anthimopoulos, S. Christodoulidis, L. Ebner, A. Christe ve S. Mougiakakou, "Lung pattern classification for interstitial lung diseases using a deep convolutional neural network," IEEE Transactions on Medical Imaging, c. 35, s. 5, ss. 1207-1216, 2016.

[15] A.M. Šimundić, "Measures of diagnostic accuracy: Basic definitions," The Electronic Journal of the International Federation of Clinical Chemistry and Laboratory Medicine, c. 19, s. 4, ss. 203, 2009.

[16] P. Eusebi, "Diagnostic accuracy measures," Cerebrovascular Diseases, c. 36, s. 4, ss. 267-272, 2013.

[17] M. Sokolova ve G. Lapalme, "A systematic analysis of performance measures for classification tasks," Information Processing \& Management, c. 45, s. 4, ss. 427-437, 2009. 